\title{
Editorial: Media neutral planning - a new role for marketing databases?
}

Tim Rivett describes media neutral planning (MNP) as being "based on a detailed understanding of key

relationships between the consumer, the brand and all potential media options'. ${ }^{1}$ From a better understanding we stand a chance of finding an insight that might lead directly to competitive advantage, and be able to capitalise on the insight with an effectively targeted media plan which produces demonstrable results.

The challenge that practitioners face, however, is that the marketing communications world can be divided into two distinct camps. Advertising planners working on above the line (ATL) campaigns and database marketing planners working on below the line (BTL) campaigns use completely different tools and methodologies to do their work. Advertisers whose communications spend is either largely ATL or BTL do not have a great need to integrate the approaches, but many major advertisers have substantial budgets for both ATL and BTL activities. For these organisations a unified approach to communications represents the holy grail of marketing planning.
As a simplified overview, the targeting and evaluation methodologies adopted by each discipline are shown in the table below.

Evaluation is very different for each of the disciplines. Practitioners from each discipline have evolved the best possible tools to meet their needs, but these methodologies are not easily interchangeable. In the ATL world it is difficult to convert attitude or awareness measures into estimates of increased sales, so advertisers seeking financial justification for their activity typically turn to econometrics.

Econometric models can (and should) incorporate below the line activity, but although the models produced give an indication of the impact of direct mail activity at a macro level, the level of detail of the answer is by necessity very coarse. Some models I have seen ignore BTL activity completely, resulting in omitted variable bias.

Econometrics allows us to compare ATL and BTL performance, and to move towards the MNP ideal. But, even if all elements of the marketing mix are considered fairly, the methodology does

\begin{tabular}{lll}
\hline & Targeting methodology & Evaluation methodology \\
\hline ATL (Broadcast) & $\begin{array}{l}\text { Demographic or behavioural target groups } \\
\text { identified in research panels (eg TGI / } \\
\text { BARB) to identify candidate media to } \\
\text { advertise in. }\end{array}$ & $\begin{array}{l}\text { Attitude or awareness shifts. } \\
\text { Econometric modelling to link advertising } \\
\text { spend to sales or market share outcome. }\end{array}$ \\
BTL (Narrowcast) & $\begin{array}{l}\text { Statistical modelling of transactional } \\
\text { and/or demographic data to identify } \\
\text { individual prospects to target. }\end{array}$ & $\begin{array}{l}\text { Test and control experiments to determine } \\
\text { return on investment. }\end{array}$ \\
\hline
\end{tabular}


not allow a detailed evaluation of direct mail segments.

Conversely, test and control methodology allows BTL performance to be assessed for very small target groups and for clear financial results to be determined. The weakness of this approach as a solution for a global MNP solution is that it cannot be applied to national advertising.

Regional experiments (direct mail plus brand advertising in one region, compared to brand advertising in another) can give some clues to the relative performance of each component of the marketing mix, but the results are not as clear cut as those from BTL, and this approach cannot be applied to long-term national campaigns.

There seems to be a methodological impasse where ATL and BTL planners are unable to compare results. While the existing discipline-specific tools will continue to be developed and used, I suspect we will need to develop hybrid methodologies to support the MNP ideal.

For advertisers in sectors where all customer transactions are recorded (eg financial services, telecomms), we have developed a methodology where the customer database forms the backbone of the evaluation approach. Instead of building an econometric model explaining sales performance for the brand as a whole, using macro measures of overall BTL and ATL activity, our approach is to use geodemographic segmentation of the customer database to build different models for different customer segments. Sales performance of individual customers, and the BTL communications they were sent, are aggregated up to a number of geodemographically defined segments.

Use of geodemographically defined segments allows us to estimate which ATL messages they may have been exposed to (the BARB TV viewing panel is coded with MOSAIC for example). We can also estimate the volume of competitive direct mail received by customer segments by analysing direct mail and insert research panels such as Thomson.

This approach allows us to improve evaluation in sectors with comprehensive transactional databases, but of course many large advertisers, for example FMCG manufacturers, do not have (and will not have for the foreseeable future) comprehensive transactional databases.

There is still a gap between the MNP ideal and the realities of today's communications planning practice. Closing this gap remains an exciting challenge, and I hope that database marketers will have a key role in developing the tools to deliver MNP.

\section{Reference}

1 Admap (2003), January, No. 435.

MARC O'REGAN

Director, Proximity London

\section{Publisher's Note}

Subscribers are advised that from the next issue, Volume 11 No 1, the Journal of Database Marketing is to change its name to the Journal of Database Marketing and Customer Strategy Management. 